\title{
Mortality of marine planktonic copepods: global rates and patterns
}

\author{
A. G. Hirst ${ }^{1, *}$, T. Kiørboe ${ }^{2}$ \\ ${ }^{1}$ Department of Biological Sciences, Heriot-Watt University, Riccarton, Edinburgh EH14 4AS, United Kingdom \\ ${ }^{2}$ Danish Institute for Fisheries Research, Charlottenlund Castle, 2920 Charlottenlund, Denmark
}

\begin{abstract}
Using life history theory we make predictions of mortality rates in marine epi-pelagic copepods from field estimates of adult fecundity, development times and adult sex ratios. Predicted mortality increases with temperature in both broadcast and sac spawning copepods, and declines with body weight in broadcast spawners, while mortality in sac spawners is invariant with body size. Although the magnitude of copepod mortality does lie close to the overall general pattern for pelagic animals, copepod mortality scaling is much weaker, implying that small copepods are avoiding some mortality agent/s that other pelagic animals of a similar size do not. We compile direct in situ estimates of copepod mortality and compare these with our indirect predictions; we find the predictions generally match the field measurements well with respect to average rates and patterns. Finally, by comparing in situ adult copepod longevity with predation-free laboratory longevity, we are able to make the first global approximations of the natural rates of predation mortality. Predation and total mortality both increase with increasing temperature; however, the proportion that predation makes of total adult mortality is independent of ambient temperature, on average accounting for around $2 / 3$ to $3 / 4$ of the total.
\end{abstract}

KEY WORDS: Copepod - Mortality - Fecundity - Development time - Sex ratio - Temperature · Body mass $\cdot$ Scaling $\cdot$ Predation

Resale or republication not permitted without written consent of the publisher

\section{INTRODUCTION}

Over the last 30 years much effort has gone into examining the growth and fecundity of marine planktonic copepods. We have a broad knowledge of rates of weight-specific growth in copepods and how, for example, in situ rates compare with those under laboratory 'food saturation' (Hirst \& Lampitt 1998). Over the same period only relatively few investigations have quantified rates of mortality, and fewer still have examined closely the possible dominant causal agents (although see Ohman 1986, Ohman \& Hirche 2001). The seasonal and spatial patterns we observe in abundance is not only controlled by the accumulation terms of growth and egg output, but also by loss through

${ }^{*}$ Present address: British Antarctic Survey, High Cross, Madingley Road, Cambridge CB3 OET, United Kingdom.

E-mail: aghi@bas.ac.uk mortality. Without an understanding of both, we will be unable to describe the factors controlling population success, make predictions of population dynamics, and develop accurate models of biomass and abundance. Furthermore, variation in mortality rates may be much greater than changes in egg production rates and more important than fecundity in determining spatio-temporal patterns in copepod abundance (Uye et al. 1992, Ohman \& Wood 1995). Measurements of mortality have lagged those of growth for a variety of reasons. Growth is a property of individuals while mortality is a population parameter. Although it is possible to estimate growth and fecundity by incubating individuals with their natural prey, an incubation approach is not feasible for estimating mortality. Natural predators can range from heterotrophic dinoflagellates to highly mobile planktivorous fish and mammals (see Ohman \& Wood 1995), whilst other agents such as loss to the benthos are excluded from most incubation methods. Direct estimates of mortality 
rates are therefore typically derived by following populations in their environment over time. This is inherently difficult and time consuming; hence, estimates of copepod mortality rates are scarce and ideas as to global in situ patterns are lacking.

In this study, we consider rates and patterns in copepod mortality estimated indirectly by a demographic approach, from field estimates of fecundity, development rates and sex ratios. For a copepod population at steady state, mortality has to be balanced by recruitment, which in turn depends only on fecundity and development time. Kiørboe \& Sabatini (1995) compiled laboratory data on food saturated fecundities and development times in copepods and found that these were invariant with body mass. They concluded that if these parameters were also independent of body mass in the field, then this would imply that mortality rates would be size independent. This is at variance with the general pattern in aquatic invertebrates and vertebrates (e.g. Peterson \& Wroblewski 1984, McGurk 1986). Aksnes (1996) argued that for copepods, size independency of growth and hence mortality is unlikely to prevail in the field. For example, large copepods may spend more time at depths where food is scarce and may therefore be more food limited, grow slower and suffer lower mortality than small species. Direct estimates of copepod mortality in the field are generally too limited in range (and environments) to allow us to examine patterns. The aims of the present study are to describe temperature and allometric (scaling) patterns of copepod mortality from indirect estimates, and to extend the temperature, body mass and environment ranges over which we have mortality estimates, thus deriving a first global framework. We also aim to compile available direct measurements of in situ mortality, thereby allowing comparisons between the 2 approaches.

\section{MATERIALS AND METHODS}

Methods. We make the assumptions that the population considered is in steady state, that the mortality rate $\beta\left(\mathrm{d}^{-1}\right)$ is age and sex independent, and that the egg production rate is constant for adult females irrespective of their age. With these assumptions the net reproductive rate $R_{0}$ (i.e. the number of offspring per female that survive until the next generation) is given by the rate of mortality, the development time $D$ in days (i.e. time from being laid as an egg to moulting into adulthood) and the egg production rate $m$ (eggs female ${ }^{-1} \mathrm{~d}^{-1}$; Kiørboe \& Sabatini 1994):

$$
R_{0}=(m / \beta) \mathrm{e}^{-\beta D}
$$

For the population to be maintained $R_{0}$ has to equal $S+1$, where $S$ is the ratio of adult males to females. Eq. (1) is used to derive mortality rate estimates for sac spawning (egg-carrying) species with no separation of eggs and post-hatch individuals.

The assumption that the mortality rate is age independent is unrealistic for broadcast spawning copepods because free eggs suffer much higher mortality rates than the post-hatched stages (e.g. Ianora \& Poulet 1993, Kiørboe \& Sabatini 1994, Peterson \& Kimmerer 1994, Liang \& Uye 1997). Separating the mortalities of eggs $\left(\beta_{\mathrm{e}}, \mathrm{d}^{-1}\right)$ and post-hatch individuals $\left(\beta_{\mathrm{h}}, \mathrm{d}^{-1}\right)$ yields (Kiørboe \& Sabatini 1994):

$$
R_{0}=\left(m / \beta_{\mathrm{h}}\right) \mathrm{e}^{-\left(\beta_{\mathrm{e}}-\beta_{\mathrm{h}}\right) \tau+\beta_{\mathrm{h}} D}
$$

The ratio of the egg hatching time $(\tau, \mathrm{d})$ to development time $(D$, days) in broadcast spawners as compiled by Kiørboe \& Sabatini $(1994,1995)$ averages $\tau / D=0.05$. If we consider this ratio representative, and further assume that free eggs have a mortality rate which is 10 times the mortality of the post-hatch stages (Kiørboe 1998, Eiane 1999), i.e. $\beta_{\mathrm{e}}=10 \beta_{\mathrm{h}}$, then Eq. (2) simplifies to:

$$
R_{0}=\left(m / \beta_{\mathrm{h}}\right) \mathrm{e}^{-1.45 \beta_{\mathrm{h}} D}
$$

Eq. (1) for sac spawners and Eq. (3) for broadcast spawners can be solved iteratively at $R_{0}=S+1$ for mortality $\left(\beta, \beta_{\mathrm{h}}\right)$ from estimates of fecundity $(m)$, development time $(D)$ and ratio of adult males to females $(S)$. Field estimates of these parameters were therefore compiled from the literature in order to estimate natural mortality rates using these equations.

Egg production rates $(\boldsymbol{m})$. All fecundity data included were for copepods collected from within the epi-pelagic zone (0 to $200 \mathrm{~m}$ ). Data on egg production rates for broadcast spawners were taken from studies where recently caught wild individuals were incubated over periods of typically $1 \mathrm{~d}$, at near in situ temperatures (i.e. within $5^{\circ} \mathrm{C}$ of their environment) and in natural seawater. If copepods were incubated for longer, then only studies where food was replaced regularly were included. Investigations where adult females were selected based on gonad maturity or reproductive output were excluded, unless egg production rates were corrected to describe all adult females regardless of their status. When females were selected on the basis of spermatophore attachment results were included, although this could potentially cause some bias. No selection took place on the grounds of the vertical location from which incubation water was taken (e.g. chlorophyll maxima, sea surface or several depths) only that it was collected from within close horizontal and vertical proximity and near simultaneously to the copepods.

Egg production data for sac spawners were taken from studies using either of 2 methods. An incubation 
approach similar to that used for broadcasters has been applied to sac spawners (e.g. Bautista et al. 1994, Calbet et al. 1996, Saiz et al. 1997, Calbet \& Agustí 1999), usually with the incubation of those individuals found to lack eggs while sorting. We include these results but appreciate that incubating egg-free females may potentially cause some bias. The other approach is the egg ratio method, in which fecundity is estimated from measurements of in situ abundances of eggs $(E)$ and females $(F)$ as well as egg hatching time, $m=E /(F \tau)$. Sometimes egg hatching time or the time interval between egg-sac production were determined on individuals collected at a single temperature and then incubated at a range of temperatures. The resulting equations are then applied to seasonal data of in situ temperature, and egg and adult abundance data (e.g. Sabatini \& Kiørboe 1994, Uye \& Sano 1995); we include such sac spawning data here.

Some of the individual values represent averages from more than 1 location and/or time; however, the majority represent collections at a single location and time. The data set arrived at includes 938 measurements of egg production from $\sim 31$ species of broadcast spawners (including 53 zero egg production values), and 166 measurements for $\sim 7$ species of sac spawners (including no zero egg production values) (see Table 1). Measurements were obtained at temperatures between -2.3 and $29^{\circ} \mathrm{C}$ for broadcasters and between 4.5 and $29.5^{\circ} \mathrm{C}$ for sac spawners, and spanned female body sizes between 2-9050 and 0.5-23 $\mu \mathrm{g}$ DW (dry weight) ind. ${ }^{-1}$ for the 2 respective groups. All data with derivation details are given in Appendix A (appendices available at: www.int-res. com/journals/suppl/Hirst Appendices.pdf).

Development time $(\boldsymbol{D})$. We compiled data from the literature on the development time of copepods in the field, or in conditions that approximate those in the field, i.e. natural seawater and natural temperature (e.g. McKinnon 1996). When development times included an over-wintering period this dormant period was not included in the full development time. The development time is by definition the period from egg laying to adulthood. In many cases the development time reported does not strictly refer to this period. For example, some workers have excluded the egg hatching time, e.g. Conover \& Huntley 1991. We only accepted studies where the time described is likely to be only a small fraction short of the total development time, e.g. N2 to C6 given as development time. In some environments, especially polar waters, development times are more poorly defined than in other environments, often because observations have been historically much more limited. This has forced us to include studies in these environments which may be less accurate and contain more assumptions (e.g. Smith 1990, Conover \& Huntley 1991). Development times, together with the definition of the development time extracted from publications, are given in Appendix B. The resulting data set includes 151 values for 32 species, in habitats ranging from the poles to the tropics, and temperatures from 0 to $29.2^{\circ} \mathrm{C}$ (Table 1 ).

Adult sex ratios (S). To solve the mortality equations, it is necessary to know the sex ratio at the point of moulting to adulthood. Unfortunately, sex ratio data at point of moult are almost entirely unavailable for field populations; rather, the 'standing' sex ratios are reported for adults. We therefore have been forced to rely upon these in our investigation. This of course will cause some error, with typical over-representation by females and under-representation by males as the former tend to live longer than the latter (Parrish \& Wilson 1978, Jacoby \& Youngbluth 1983), but this will be minor with respect to the mortality rates derived. Again we attempted to limit our selection to epipelagic studies. Data were compiled from 19 publications with sex ratios for $\sim 35$ species and including 3927 individual measurements, all measurements are detailed in Appendix C.

Table 1. Summary of the data set compiled from the literature of quasi-in situ measurements of fecundity, development time and adult sex ratios of marine epi-pelagic copepods (Appendices A to C)

\begin{tabular}{|c|c|c|c|c|}
\hline Measurement & No. of species & $\begin{array}{l}\text { No. of data points } \\
\text { (no. of zero values) }\end{array}$ & $\begin{array}{l}\text { Temperature range } \\
\left({ }^{\circ} \mathrm{C}\right)\end{array}$ & $\begin{array}{l}\text { Body weight range } \\
\left(\mu \mathrm{g} \text { DW ind. }{ }^{-1}\right)\end{array}$ \\
\hline \multicolumn{5}{|c|}{ Development time $(D)$} \\
\hline Broadcasters & $\sim 19$ & 107 & $0-29.2$ & $1.1-1900$ \\
\hline Sac spawners & $\sim 12$ & 46 & $2.6-28$ & $0.60-132.8$ \\
\hline \multicolumn{5}{|l|}{ Fecundity (m) } \\
\hline Broadcasters & $\sim 31$ & $938(53)$ & $-2.3-29$ & $2.0-9050$ \\
\hline Sac spawners & $\sim 7$ & $166(0)$ & $4.5-29.5$ & $0.5-23$ \\
\hline \multicolumn{5}{|c|}{ Adult sex ratio $(S)$} \\
\hline Broadcasters & $\sim 21$ & 56 & - & - \\
\hline Sac spawners & $\sim 15$ & 25 & - & - \\
\hline
\end{tabular}


Predicted mortality. For every egg production rate measurement $\left(m\right.$, eggs female $\left.{ }^{-1} \mathrm{~d}^{-1}\right)$ we calculated a mortality value using the mean $(S+1)$ value, and the predicted development time $(D$, days) derived from the regression describing development time as a function of temperature and adult body weight (see 'Statistical analyses' section). Observations of zero egg production do not produce mortality estimates and therefore had to be removed in this 'full' data set approach. Upper and lower ranges to each individual mortality prediction were made using reasonable absolute limits to the sex ratios (discussed later) and the standard error limits of development times.

The above approach potentially has several flaws. The data are dominated by some species over others, which could give a biased view. Furthermore, zero egg production values do not return a mortality rate and have to be removed, these are thus not represented in the regression analyses. Therefore, to determine if between-species patterns are similar to the pattern of

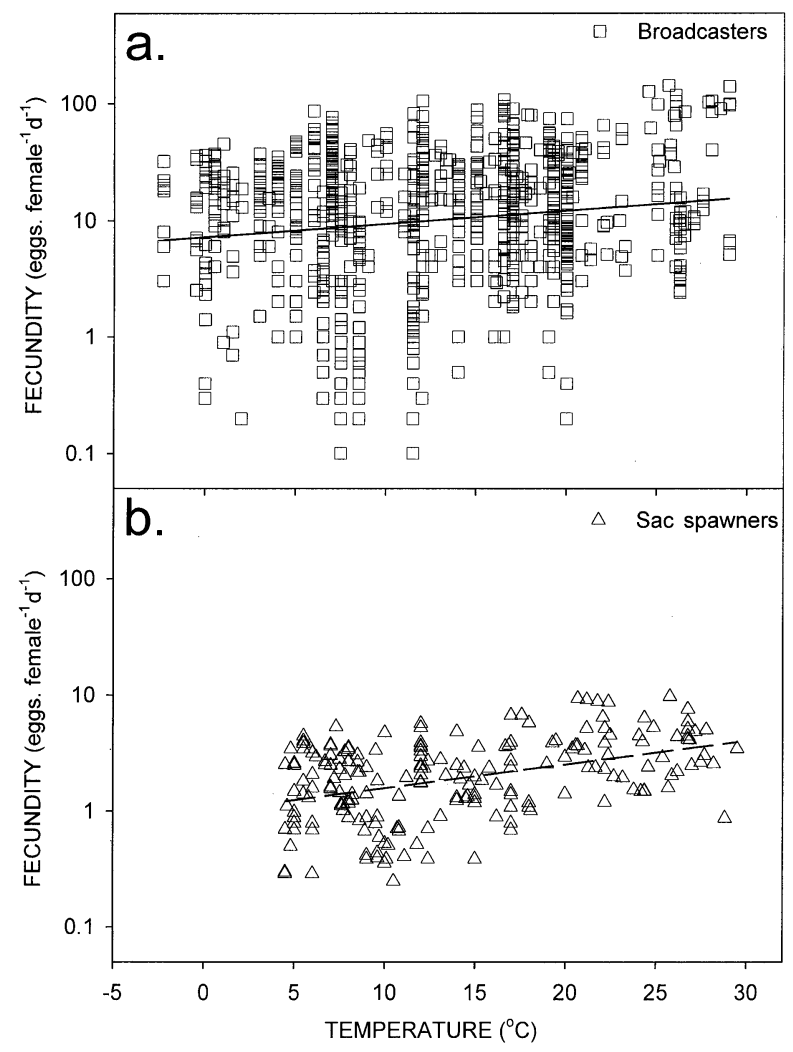

Fig. 1. Egg production rates in adult female epi-pelagic copepods as a function of temperature in (a) broadcast spawners $(\square)$ and (b) sac spawner $(\Delta)$ species. Logarithmic regressions of fecundity ( $m$, eggs female ${ }^{-1} d^{-1}$ ) versus temperature $\left(T,{ }^{\circ} \mathrm{C}\right)$ given by solid line for the broadcasters $\left[\log _{\mathrm{e}} m=0.0266 T+1.9708\right]\left(\mathrm{r}^{2}=0.0210, \mathrm{n}=885, \mathrm{p}<0.001\right)$ and by dashed line for sac spawners $\left[\log _{\mathrm{e}} m=0.0468 \mathrm{~T}-0.01977\right]$ $\left(\mathrm{r}^{2}=0.175, \mathrm{n}=166, \mathrm{p}<0.001\right)$ the entire data set, and to explore the consequences of species average egg production rates including zero values, we derived average mortality rates for each species. Two methods were used, both of which were chosen to allow inclusion of zero egg production values, which should more closely represent the steady state situation. Firstly, to allow a comparison of mortality against body weight for each species, each individual egg production rate was corrected to $15^{\circ} \mathrm{C}$ using a $Q_{10}$ of 1.3 for broadcast spawners and 1.6 for sac spawners (see Fig. 1). Mortality rates were then derived for each species from the average of its temperature corrected egg production rates $\left(15^{\circ} \mathrm{C}\right)$, and the predicted development time at $15^{\circ} \mathrm{C}$. Secondly, to allow comparison of mortality against temperature, for each species the arithmetic mean temperature at which egg production rate values had been determined was derived, each egg production rate was then corrected to this mean temperature (again using a $Q_{10}$ of 1.3 for broadcast spawners and 1.6 for sac spawners), and finally these corrected egg production values were averaged for the species. These rates together with appropriate development time were used to derive individual species' mortality rates. This second data set was also used in the multiple linear regression described later in the 'Statistical analyses' section as it allows mortality to be described as a function of both body weight and temperature.

Field measurements of mortality. We compiled field measurements of mortality for broadcast and sac spawners from the literature. We excluded any values that represented over-wintering mortality at great depths, or mortality for meso-pelagic populations, as we are making epi-pelagic comparisons here. For the broadcasters we separated egg and post-hatch mortality rates. We added to the reported egg mortality measurements by making calculations from published data when the appropriate information was available, i.e. egg production rates estimated simultaneously from the incubation approach $\left(m_{\mathrm{I}}\right)$ and the egg ratio method $\left(m_{\mathrm{ER}}\right)$ (Beckman \& Peterson 1986, Liang et al. 1994, Gómez-Gutiérrez \& Peterson 1999). In these cases, we derived egg mortality $\left(\beta_{\mathrm{e}}, \mathrm{d}^{-1}\right)$ by solving the following equation (modified and corrected from Peterson \& Kimmerer 1994) by iteration:

$$
\frac{m_{\mathrm{ER}} \beta_{\mathrm{e}} \tau}{m_{\mathrm{I}}}=1-\mathrm{e}^{-\beta_{\mathrm{e}} \tau}
$$

It was not possible to distinguish studies in which advective loss may have been important from those in which it may not; relevant measurements of such terms were not available in the original studies and differentiation would have been subjective. For these reasons, we did not exclude any values on the grounds of advection. For broadcast species, 
we obtained a total of 73 egg mortality estimates in 4 species, and 497 measurements of post-hatch mortality estimates in 11 species. For sac spawners, we compiled 123 mortality estimates, but these were from only 3 species and 106 of these were for a single species, Eurytemora affinis. The entire data set almost exclusively comprised small species, adult weights only covered the range 5 to $645 \mu \mathrm{g}$ DW ind. ${ }^{-1}$. The temperatures range was extensive, from 0.5 to $29.2^{\circ} \mathrm{C}$.

Field and laboratory measurements of adult longevity. We compiled both field and laboratory adult longevity measurements from the literature. When laboratory values were measured as a function of food concentration, we took those values at the highest food concentration (e.g. Nival et al. 1990, Sabatini \& Kiørboe 1994). We did not include studies where adult longevity was measured for starved individuals (e.g. Corkett \& Urry 1968, Borchers \& Hutchings 1986). A total of 182 measurements in the field were included, but these comprised only 7 species, all of which were broadcasters. From the laboratory, we found 73 measurements in 21 species in total, of this total 35 measurements and 11 species were sac spawners.

To allow a comparison between directly estimated longevities and mortality rates predicted by us from demographic observations, adult longevity $(L)$ was derived from the latter as $L=\beta^{-1}$.

Temperature and body weight. All observations of fecundity, development rate and mortality were related to female body weight and temperature. Adult body weights were taken from the same paper that had reported the vital rates, or by using species-specific average values from the compilation of Kiørboe \& Sabatini (1995), or other relevant studies (all sources and calculations are detailed in the Appendices). Carbon weight was assumed to be $40 \%$ of dry weight (Omori \& Ikeda 1984, Båmstedt 1986) and ash-free dry weight $89 \%$ of dry weight (Båmstedt 1986). Species-specific egg weights were taken from Appendix 1 of Kiørboe \& Sabatini (1995) or Table A1 of Huntley \& Lopez (1992). If no species-specific values were available, we predicted egg size from an equation relating egg size to adult size (Kiørboe \& Sabatini 1995).

Statistical analyses. Dependencies on temperature and body mass were examined by backwards stepwise regression where $F$-to-enter was set at 4.0 , and $F$-toremove set at 3.9. Multiple linear regressions were conducted using SigmaStat (SPSS). The general model used for regression analyses was: $V=a \mathrm{e}^{b T} \mathrm{DW}^{c}$, or after $\log _{\mathrm{e}}$ transformation: $\log _{\mathrm{e}} V=\log _{\mathrm{e}} a+b T+c \log _{\mathrm{e}}$ DW, where $a, b$, and $c$ are coefficients, $T=$ temperature $\left({ }^{\circ} \mathrm{C}\right), \mathrm{DW}=$ female body weight $\left(\mu \mathrm{gDW}\right.$ ind $\left.{ }^{-1}\right)$, and $V$ is either fecundity (eggs female $\mathrm{e}^{-1} \mathrm{~d}^{-1}$ ), development time $(d)$ or mortality $\left(d^{-1}\right)$.

\section{RESULTS}

\section{Egg production rates}

Rates of egg production are very variable but are also typically almost an order of magnitude higher in broadcasters than in sac spawning species. Fecundity increases significantly with temperature in both groups (Fig. 1) as revealed by simple log regressions. The $Q_{10}$ values determined from the relationship between fecundity and temperature are relatively low, being 1.30 for broadcast spawners and 1.60 for sac spawners. There is a significant increase in fecundity with body mass in sac spawners, while the relationship is insignificant in broadcasters (Fig. 2). This is also confirmed by step-wise multiple regression, where body weight is removed as an independent variable for the broadcast spawners but retained in sac spawners (Table 2).

\section{Development time}

Development time decreases with increasing temperature and increases with body weight in both broadcast and sac spawning copepods (Fig. 3). Data from sac and broadcast spawners were pooled. Stepwise multiple regression using the pooled data demonstrates that both temperature and body weight effects are significant (Table 2).

\section{Sex ratio}

The mean sex ratios for broadcast and sac spawners both differed significantly from 1:1 and they also differed significantly from one another, with more females for every male on average in the broadcasters ( $t$-test on arcsine transformed proportion of female values; $\mathrm{p}=0.025)$. However, we use the overall average $R_{0}$ value of 1.5 (i.e. 1 male for every 2 females) as the difference between the 2 groups is small $(1.6 \pm 0.4$ and $1.3 \pm 0.2$, mean \pm SD for broadcast and sac spawners respectively). To give upper and lower ranges in the mortality calculations we use $R_{0}$ values of 0 (i.e. $100 \%$ females) and 2.0 (i.e. 2 males for every 1 female). This range covers the mean sex ratios for all the species we have compiled values for. The $R_{0}$ value cannot fall below 0 , and the highest value we found was 1.8 for Centropages hamatus.

\section{Predicted mortality}

The equations used to predict mortality and its upper and lower limits are given in Table 3. Results from 


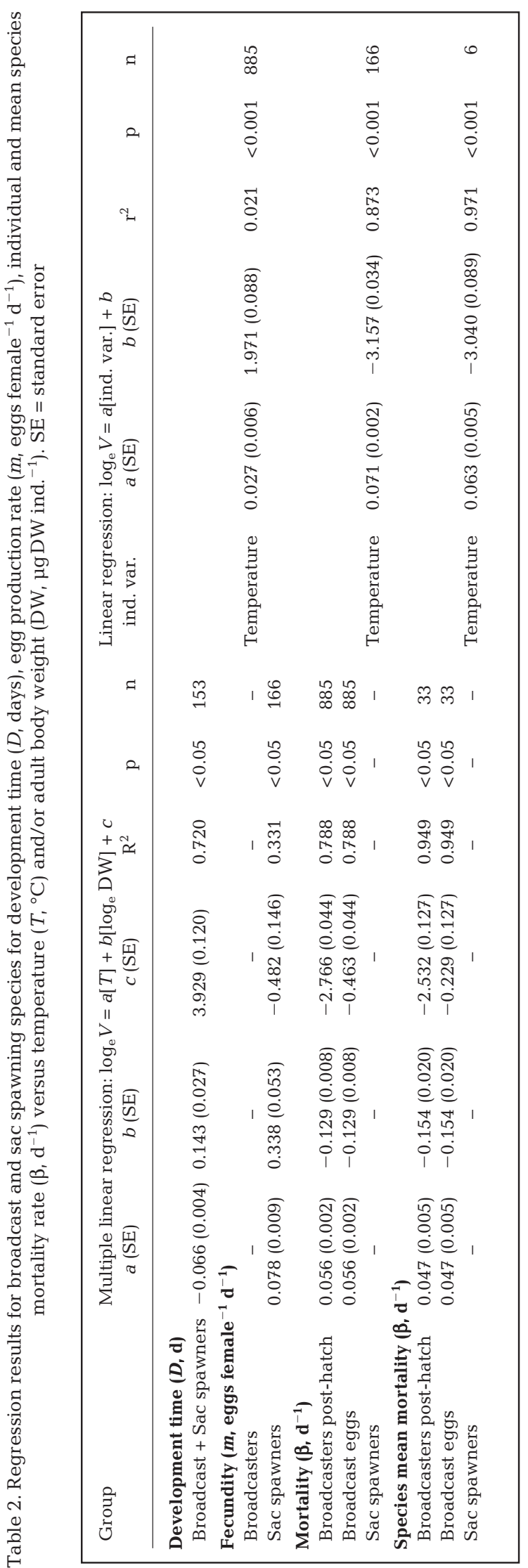

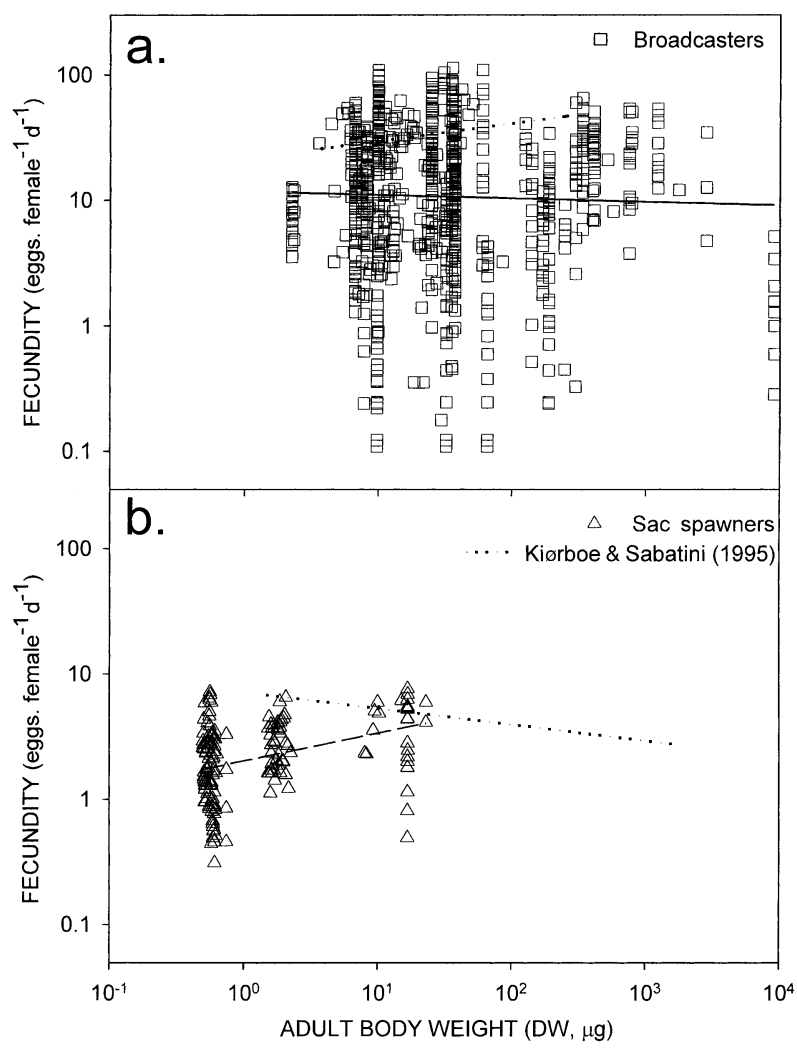

Fig. 2. Egg production rates in adult female epi-pelagic copepods as a function of body dry weight. All rates corrected to $15^{\circ} \mathrm{C}$ using $Q_{10}$ values of 1.3 for broadcasters and 1.6 for sac spawners (as revealed by the analysis in Fig. 1). (a) Broadcast spawners $(\square)$ and (b) sac spawners $(\Delta)$. Log regressions of fecundity ( $m$, eggs female $\mathrm{e}^{-1} \mathrm{~d}^{-1}$ ) versus adult body dry weight (DW, $\mu \mathrm{g}$ ind. $^{-1}$ ) given by solid line for the broadcasters, $\log _{10} m=-0.028 \log _{10} \mathrm{DW}+1.071\left(\mathrm{r}^{2}=0.001, \mathrm{n}=885, \mathrm{p}>0.20\right.$ ns) and by dashed line for sac spawners, $\log _{10} m=$ $0.221 \log _{10} \mathrm{DW}+0.307\left(\mathrm{r}^{2}=0.139, \mathrm{n}=166, \mathrm{p}<0.001\right)$. Laboratory 'food saturated' relationships from Kiørboe \& Sabatini (1995) are given for comparison

species averages are very close to those derived from the entire data set (see Figs. $4 \& 5$, Table 2). We use the relationships derived from the individual measurements rather than species means in the remainder of this paper, this is justified given the very close similarity in the relationships of the two.

Mortality rates predicted from the individual fecundities, mean sex ratio and case-specific estimates of development times increase significantly with temperature in both sac and broadcast spawning copepods (Fig. 4). Post-hatch mortality rates are similar among the 2 spawning groups and approximately double with a $10^{\circ} \mathrm{C}$ increase in temperature in both $\left(Q_{10}\right.$ of 2.06 and 2.03 for broadcasters and sac spawners respectively). Mortality is independent of body weight in sac spawners, but decreases significantly with body weight in broadcasters (Table 2). 


\section{Comparison of predicted and observed mortality rates}

It is important to appreciate (and for us to make clear) that the observed scatter in rates of predicted mortality for the individual rates (Figs. 4a,b \& 5a,b) will not be indicative of the variability one might observe for shortterm measurements in situ. Rather our predictions allow examination of the steady state patterns and average rates of mortality, for example, they give an insight to mortality with respect to body mass scaling and temperature, and the regression analyses will give 'central tendencies' of mortality in relation to these factors.

Direct estimates of mortality rates in the field (see Appendix D) show temperature and body mass dependencies that are consistent with those we predict indirectly using demographic considerations. Predicted mortality patterns for sac spawners and for post-hatch broadcasters are generally very similar to the average pattern observed in the field measurements (Fig. 6). Predicted rates for post-hatch broadcasters tend to be lower than the measured rates at the highest temperatures, and a regression through the measured posthatch mortality rates gives a value for mortality of $0.66 \mathrm{~d}^{-1}$ at $29^{\circ} \mathrm{C}$, whilst our prediction is $0.24 \mathrm{~d}^{-1}$. However, all measured rates at $>22^{\circ} \mathrm{C}$ are from 1 study in the shallow Patuxent River estuary on 1 species, namely Acartia tonsa (Heinle 1969).

Direct estimates of the mortality of free eggs of broadcasters tend to be higher than those predicted. A regression through the field measurements yields a relationship that gives mortality rates that are up to 3 times higher than the predicted rates (over the range of the regression line). Many of the highest field egg mortality rates come from 1 species in 1 study (Centropages abdominalis, Liang et al. 1994). We shall return to the topic of measuring mortality rates in free eggs and their derivation in the 'Discussion'.

Direct longevity estimates for field populations (Appendix E) show a pattern similar to the predicted values (Fig. 7), while laboratory populations show longer adult longevity than predicted, which is not sur-
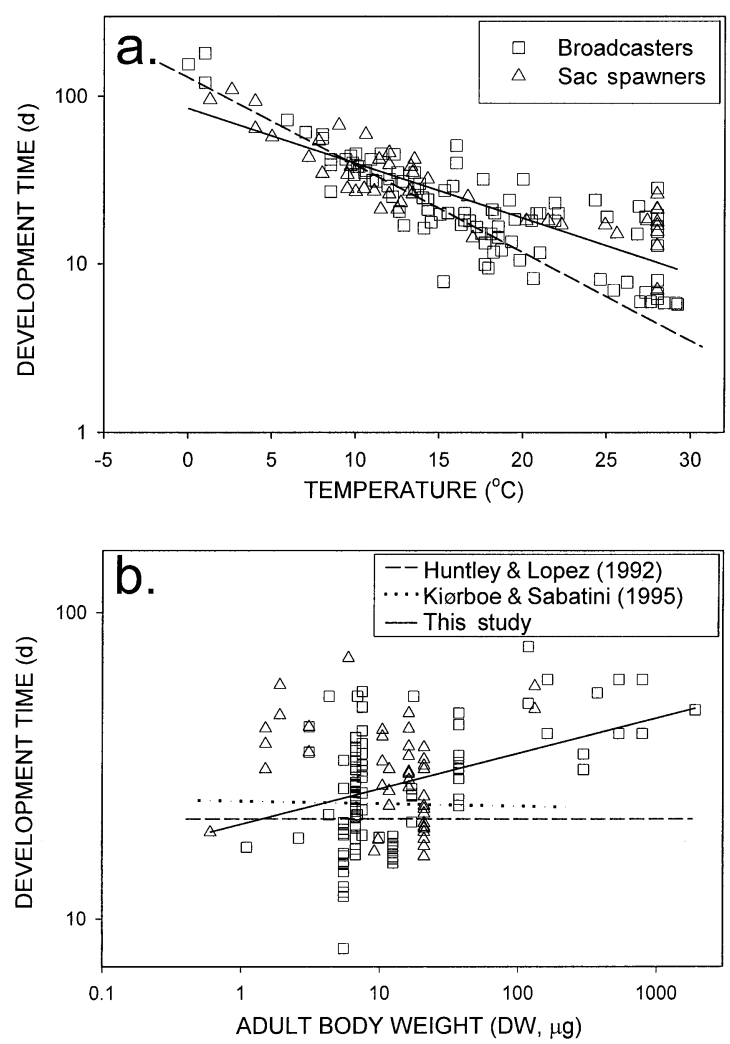

Fig. 3. (a) Development times for broadcast ( $\square$ ) and sac spawner $(\Delta)$ copepods as a function of temperature. Log regression of development time $(D$, days) versus temperature $\left({ }^{\circ} \mathrm{C}\right)$ from our results given by solid line, $\log _{\mathrm{e}} D=-0.076 \mathrm{~T}+$ $4.438\left(\mathrm{r}^{2}=0.666, \mathrm{n}=151, \mathrm{p}<0.001\right)$. (b) Development times for marine copepods as a function of adult body dry weight $\left(\mathrm{DW}, \mu \mathrm{g}\right.$ ind. $\left.{ }^{-1}\right)$, with development rates being corrected to $15^{\circ} \mathrm{C}$ using a $Q_{10}$ value of 0.46 (as revealed by the analysis in Fig. 3a). For comparison, the labotatory 'food saturated' relationship of Kiørboe \& Sabatini (1995) is given as a dotted line, and the 'commonly food saturated' relationship of Huntley \& Lopez (1992) is given as a dashed line

prising. Laboratory observations demonstrate a temperature dependency that is very similar to that predicted, i.e. the lines are parallel (Fig. 7). Thus, generally, the indirectly predicted and the direct field

Table 3. Equations used to predict the means and upper and lower ranges of mortality for broadcasters post-hatch ( $\left.\beta_{\mathrm{h}}\right)$, broadcast eggs $\left(\beta_{\mathrm{e}}\right)$ and sac spawners $(\beta)$ from development time $(D, \mathrm{~d})$, egg production rate $\left(m\right.$, eggs female $\left.\mathrm{d}^{-1}\right)$ and $R_{0}$. Development time is derived as a function of temperature $\left(T,{ }^{\circ} \mathrm{C}\right)$ and adult body weight (DW, $\mu \mathrm{gDW}$ ind. ${ }^{-1}$ )

\begin{tabular}{|c|c|c|c|c|c|c|c|}
\hline \multirow[t]{2}{*}{ Group } & \multirow{2}{*}{$\begin{array}{l}\text { Equation } \\
\text { form }\end{array}$} & \multicolumn{2}{|c|}{$\longrightarrow$ Mean $\longrightarrow$} & \multicolumn{2}{|c|}{$\longrightarrow$ Upper range -} & \multicolumn{2}{|c|}{ Lower range -} \\
\hline & & $R_{0}$ & $\mathrm{D}$ & $R_{0}$ & $\mathrm{D}$ & $R_{0}$ & $\mathrm{D}$ \\
\hline $\begin{array}{l}\text { Broadcasters } \\
\text { post-hatch }\end{array}$ & $R_{0}=\left(m / \beta_{h}\right) \mathrm{e}^{-\left(1.45 \beta_{h} D\right)}$ & 1.5 & $\mathrm{e}^{-0.06641(T)+0.1432\left(\log _{\mathrm{e}} \mathrm{DW}\right)+3.9290}$ & 1.0 & $\mathrm{e}^{-0.0708(T)+0.1165\left(\log _{\mathrm{e}} \mathrm{DW}\right)+3.8095}$ & 3.0 & $\mathrm{e}^{-0.0621(T)+0.1699\left(\log _{\mathrm{e}} \mathrm{DW}\right)+4.0485}$ \\
\hline Broadcast egg & $\beta_{\mathrm{e}}=\beta_{h} \times 10$ & 1.5 & $\mathrm{e}^{-0.06641(T)+0.1432\left(\log _{\mathrm{e}} \mathrm{DW}\right)+3.9290}$ & 1.0 & $\mathrm{e}^{-0.0708(T)+0.1165\left(\log _{\mathrm{e}} \mathrm{DW}\right)+3.8095}$ & 3.0 & $\mathrm{e}^{-0.0621(T)+0.1699\left(\log _{\mathrm{e}} \mathrm{DW}\right)+4.0485}$ \\
\hline $\begin{array}{l}\text { Sac spawners } \\
\text { (all stages) }\end{array}$ & $R_{0}=(m / \beta) \mathrm{e}^{-\beta D}$ & 1.5 & $\mathrm{e}^{-0.06641(T)+0.1432\left(\log _{\mathrm{e}} \mathrm{DW}\right)+3.9290}$ & 1.0 & $\mathrm{e}^{-0.0708(T)+0.1165\left(\log _{\mathrm{e}} \mathrm{DW}\right)+3.8095}$ & 3.0 & $\mathrm{e}^{-0.0621(T)+0.1699\left(\log _{\mathrm{e}} \mathrm{DW}\right)+4.0485}$ \\
\hline
\end{tabular}




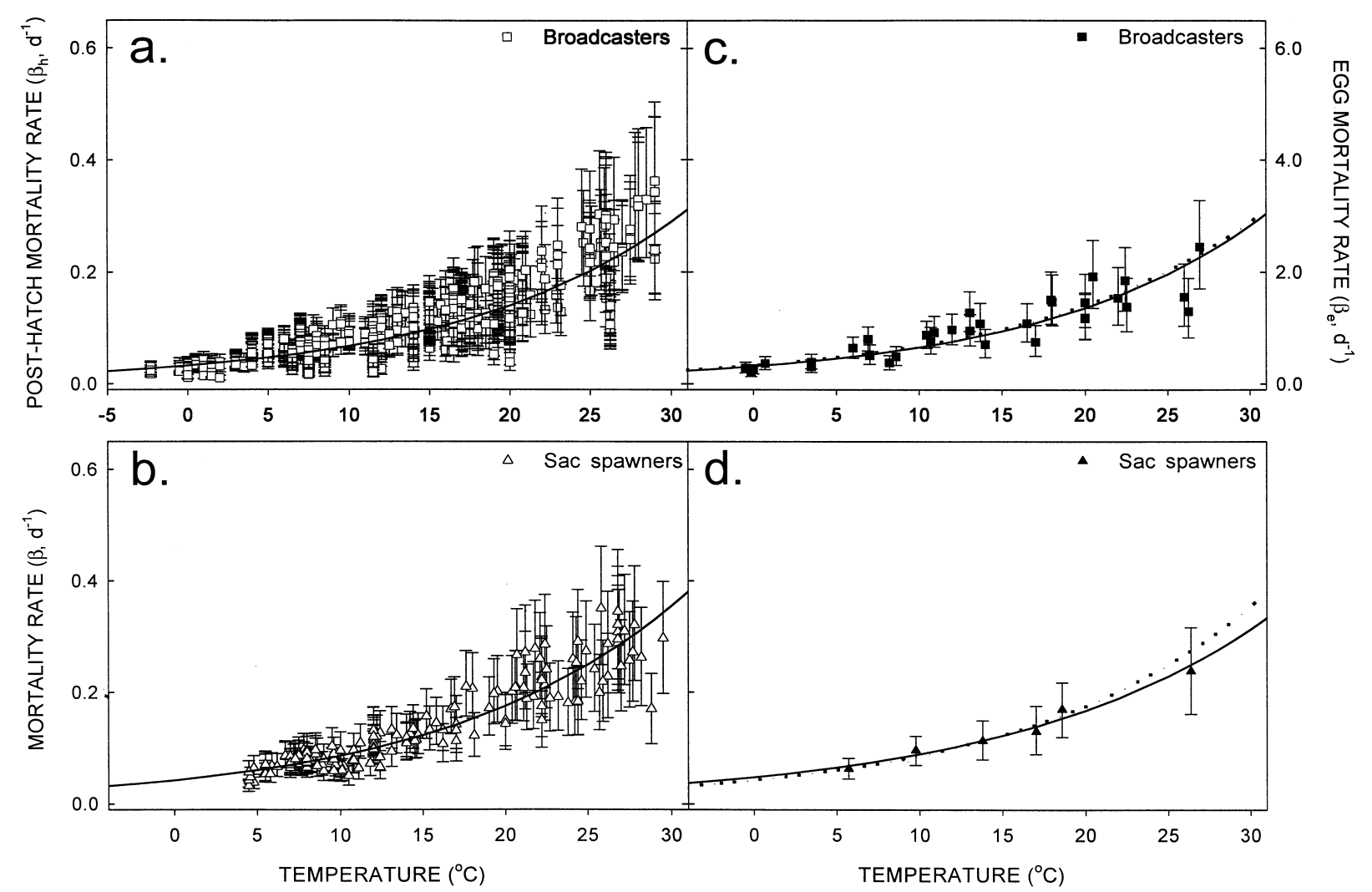

Fig. 4. Copepod mortality rates as a function of temperature. Regression analyses completed on $\log _{\mathrm{e}}$ mortality $\left(\beta, \mathrm{d}^{-1}\right)$ versus temperature $\left(T,{ }^{\circ} \mathrm{C}\right)$. (a) Broadcasters $(\square)$ yield the relationships $\log _{\mathrm{e}} \beta=0.0725 T-1.112\left(\mathrm{r}^{2}=0.723, \mathrm{n}=885, \mathrm{p}<0.001\right)$ for eggs, and $\log _{\mathrm{e}} \beta=0.0725 T-3.415\left(\mathrm{r}^{2}=0.723, \mathrm{n}=885, \mathrm{p}<0.001\right)$ for post-hatch individuals. (b) Sac spawners $(\Delta)$ yield the relationship $\log _{\mathrm{e}} \beta=$ $0.0707 T-3.157\left(\mathrm{r}^{2}=0.873, \mathrm{n}=166, \mathrm{p}<0.001\right)$. (c) Species means for broadcasters ( $\left.\mathbf{\square}\right)$ yield the relationships $\log _{\mathrm{e}} \beta=0.0730 \mathrm{~T}-1.150$ $\left(r^{2}=0.842, n=33, p<0.001\right)$ for eggs, and $\log _{e} \beta=0.0730 T-3.453\left(r^{2}=0.842, n=33, p<0.001\right)$ for post-hatch individuals. Regression from (a) is given by a dotted line for comparative purposes. (d) Species means for sac spawners ( $\mathbf{\Delta}$ ) yield the relationship $\log _{\mathrm{e}} \beta$ $=0.0627 T-3.040\left(r^{2}=0.971, n=6, p<0.001\right)$. Regression from (b) is given by a dotted line for comparative purposes. In all cases, vertical bars give the extent of the upper and lower prediction ranges; see text for details

estimates adult longevity are consistent with one another. Unfortunately the field values available are generally insufficient to establish body mass scaling rules to compare against our predictions.

\section{DISCUSSION}

\section{Assumptions}

Mortality rates of copepods are difficult to measure in the natural environment. Incubation approaches are generally inadequate and it is typically necessary to follow a population over (long) periods of time in the environment to provide estimates. Accurate measurements can only be made when one can follow distinct cohorts through time (horizontal life-table approach), or if one can assume steady state (vertical life-table approach), or we have detailed measure- ments of stage structure and stage durations over time (population surface method). Growth and fecundity rates, in contrast, can reliably be measured in incubation experiments. As a consequence, there are many studies of copepod fecundity and growth in the field, but very few that include mortality derivations. Here, we have used an indirect approach to estimate mortality from development and fecundity observations in an attempt to derive the average patterns of mortality in diverse environment types. This approach is based on 2 main assumptions: (1) posthatch mortality is constant in broadcasters, and constant in all stages (eggs and post-hatch) in sac spawners; and (2) the populations considered are in steady state. Mortality rates may be age or stage dependent in some species and in particular situations or environments (e.g. Landry 1978, Ohman \& Wood 1996, Takahashi \& Ohno 1996) but appear in fact to be similar for nauplii and copepodites on average (Kiør- 


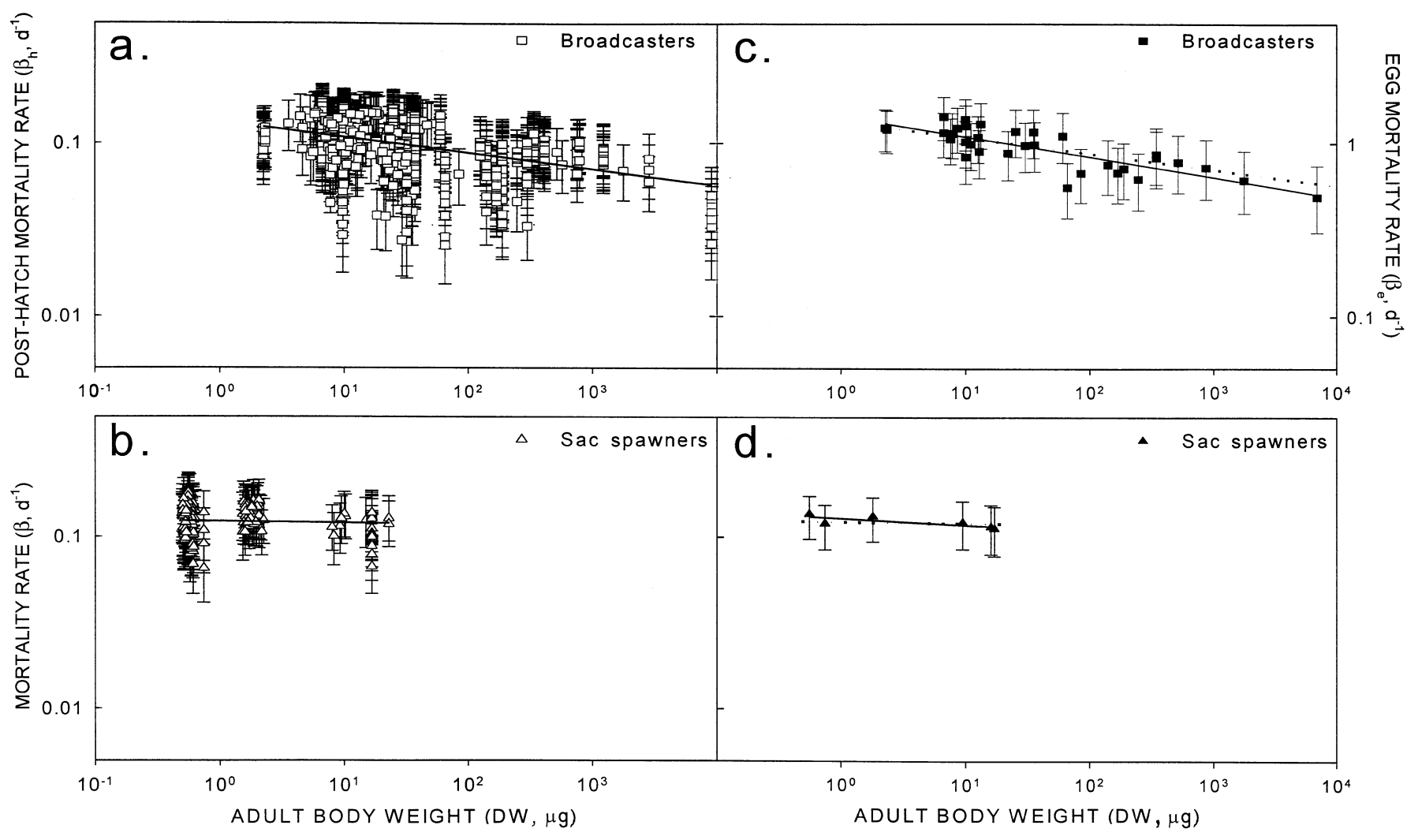

Fig. 5. Copepod mortality rate $\left(\beta, d^{-1}\right)$ as a function of adult body dry weight (DW, $\mu g$ ind. $\left.{ }^{-1}\right)$. (a) Broadcast spawners ( $\square$ ). The regression line is $\log _{10} \beta=-0.092 \log _{10} \mathrm{DW}+0.126\left(\mathrm{r}^{2}=0.185, \mathrm{n}=885, \mathrm{p}<0.001\right)$ for eggs and $\log _{10} \beta=-0.092 \log _{10} \mathrm{DW}-0.874$ for post-hatch individuals (solid line). (b) Sac spawners $(\Delta)$. The regression line is $\log _{10} \beta=-0.0085 \log _{10} \mathrm{DW}-0.910\left(\mathrm{r}^{2}=0.003\right.$, $\mathrm{n}=166, \mathrm{p}>0.50 \mathrm{~ns}$ ) (solid line). Vertical bars give the extent of the upper and lower prediction ranges (see text for details). Data corrected to $15^{\circ} \mathrm{C}$ using a $Q_{10}$-value of 2.0 (estimated from the analyses in Fig. 4). (c) Species means for broadcast spawners $(\mathbf{\square})$. The regression line is $\log _{10} \beta=-0.1174 \log _{10} \mathrm{DW}+0.158\left(\mathrm{r}^{2}=0.662, \mathrm{n}=33, \mathrm{p}<0.001\right)$ for eggs and $\log _{10} \beta=$ $-0.1174 \log _{10} \mathrm{DW}-0.842\left(\mathrm{r}^{2}=0.662, \mathrm{n}=33, \mathrm{p}<0.001\right)$ for post-hatch individuals (solid line). Dotted line gives regression from (a) for comparative purposes. (d) Species means for sac spawners $(\mathbf{\Delta})$. The regression $\operatorname{line}$ is $\log _{10} \beta=-0.0387 \log _{10} \mathrm{DW}-0.889$ $\left(\mathrm{r}^{2}=0.601, \mathrm{n}=6, \mathrm{p}>0.05 \mathrm{~ns}\right)$ (solid line). Dotted line gives regression from (b) for comparative purposes

boe 1998). The assumption of steady state is clearly violated in most dynamic situations, and we appreciate and stress that our indirect mortality rate estimates may be very different from time- and sitespecific rates measured in the field over short periods; these can be very variable spatio-temporally as a result of patchy food, predation and cannibalism for example. However, the assumption of steady state must be true for field rates if averaged over sufficiently long periods and large areas, and averages and trends in our indirect mortality estimates may be representative of the general underlying patterns. Ideally, we should have used average adult life-time fecundity in our model, but we are limited by the data in the literature, and such measurements are very rare. The few values available have typically been derived under laboratory conditions (e.g. Corkett \& Zillioux 1975, Sekiguchi et al. 1980, Uye 1981), or through incubations that would have excluded natural mortal- ity agents. These are therefore inappropriate for the prediction of in situ mortality rates.

The few direct estimates of copepod mortality rates available are almost exclusively from shallow coastal environments, estuaries and embayments (although see Ohman \& Hirche 2001). We do not know how typical mortality rates in these areas might be of other ocean areas; these shallow locations have often been described as aberrant (Landry 1978, Kimmerer \& McKinnon 1987). Our indirect estimates of mortality rate derived herein may to some extent suffer from the same bias of over-representation of coastal areas and neritic species, but the diversity in species, body sizes, environments and temperature in this data set is still much larger. They are therefore arguably better suited to establish first global temperature and scaling relationships given the current data constraints. It is encouraging that the indirect predictions and the direct measures match in pattern well. 

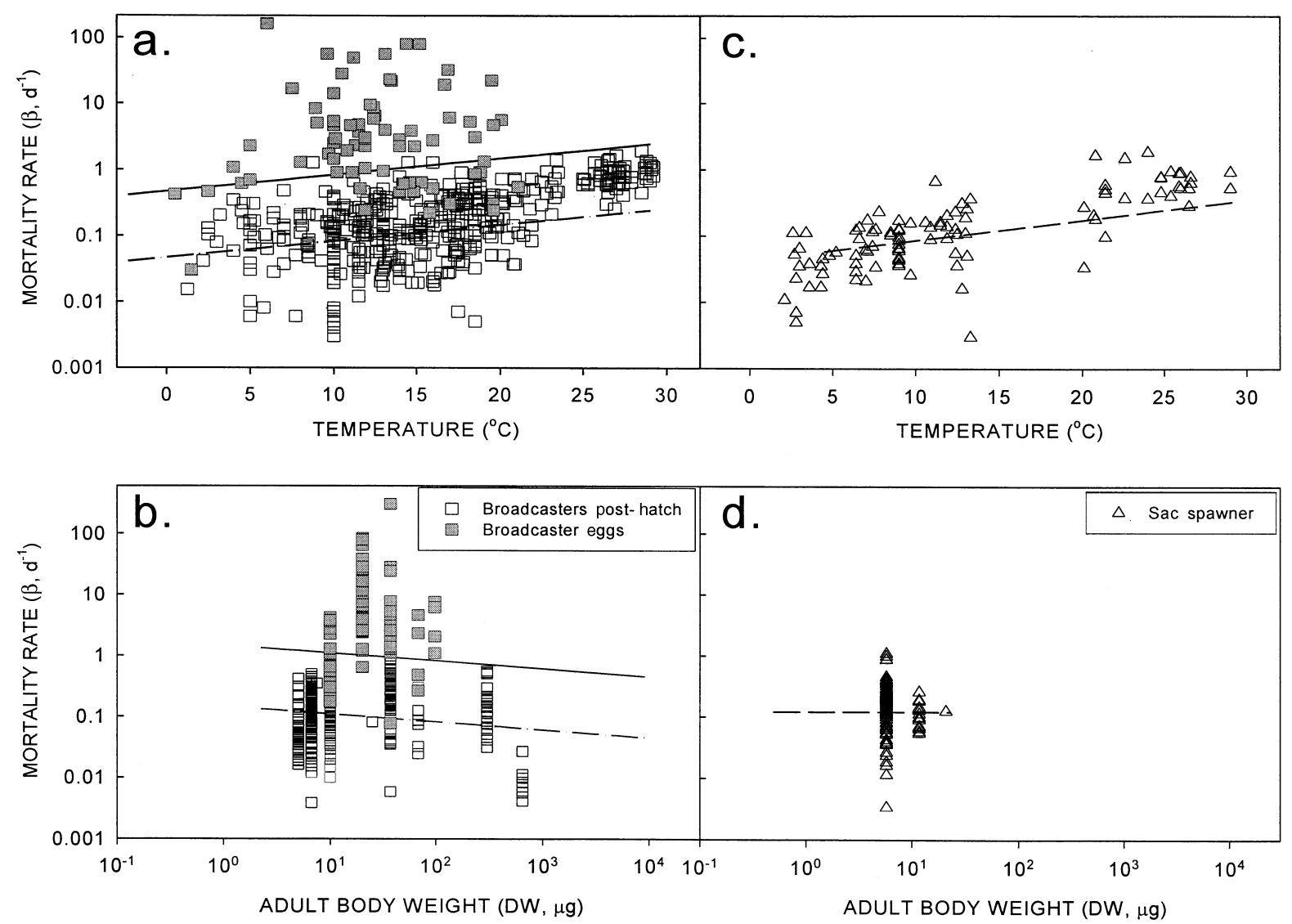

Fig. 6. Field measurements of mortality rates for broadcast eggs ( $\square$ ) and broadcasters post-hatch ( $\square$ ) plotted as a function of (a) temperature $\left({ }^{\circ} \mathrm{C}\right.$ ) and (b) adult body dry weight (DW, $\mu \mathrm{g}$ ind.$^{-1}$ ) after correction to $15^{\circ} \mathrm{C}$ using a $Q_{10}$ of 2.0 (estimated from the analyses in Fig. 4). Field measurements of mortality rates of sac spawners $(\Delta)$ plotted as a function of $(\mathrm{c})$ temperature $\left({ }^{\circ} \mathrm{C}\right)$ and (d) adult body weight (DW, $\mu \mathrm{g}$ ind.$^{-1}$ ) after correction to $15^{\circ} \mathrm{C}$. The lines are predicted mortality rates for broadcast eggs (solid line), broadcasters post-hatch (dot-dashed line), and sac spawners (dashed line) are given for comparison for a $10 \mu \mathrm{g}$ DW individual $(\mathrm{a}, \mathrm{c})$ and at $15^{\circ} \mathrm{C}(\mathrm{b}, \mathrm{d})$. In all cases, predictions were made only within the limits of the regression analysis presented in Figs. 4a,b \& 5a,b

\section{Scaling of copepod mortality}

Kiørboe \& Sabatini (1995) found no evidence of body size dependent mortality in copepods using the same demographic approach as here (i.e. predicting mortality from development time and egg production rates). However, they compiled estimates of egg production rates and development times from 'food saturated' laboratory experiments, and these were found to be size independent. Hence, the estimated mortality predicted from laboratory values was found to be size independent (cf. Eqs. 1 \& 3). Huntley \& Lopez (1992) also found that development times (mainly derived from laboratory observations) were size independent (although see arguments of Hirst \& Sheader 1997). The field data compiled here suggest firstly that the average in situ egg production rates in broadcast spawners are a factor of $\sim 5$ less than the maximum rates measured in the laboratory (Fig. 2a), thus allowing less room for mortality in field populations than laboratory measurements would suggest. In contrast, in situ fecundities of sac spawners are not very different from those maximally measured in the laboratory (Fig. 2b). Secondly, in situ fecundity and development time both increase with body mass in sac spawners. Increasing fecundity implies increased mortality, and increased development time implies decreased mortality (cf. Eqs. 1 \& 3). Thus, the trends in fecundity and development time with body size have partly counteracting effects on mortality estimates in the sac spawners. As a result, mortality decreases only slightly with size in broadcast spawners and not at all in sac spawners (Fig. 5, Table 2). Thus, with respect to scaling, the result for field populations is not that different from the result of Kiørboe \& Sabatini (1995).

When measuring mortality in field populations, these values may be increased by the advection of individuals away from a study area (of course advection of indi- 

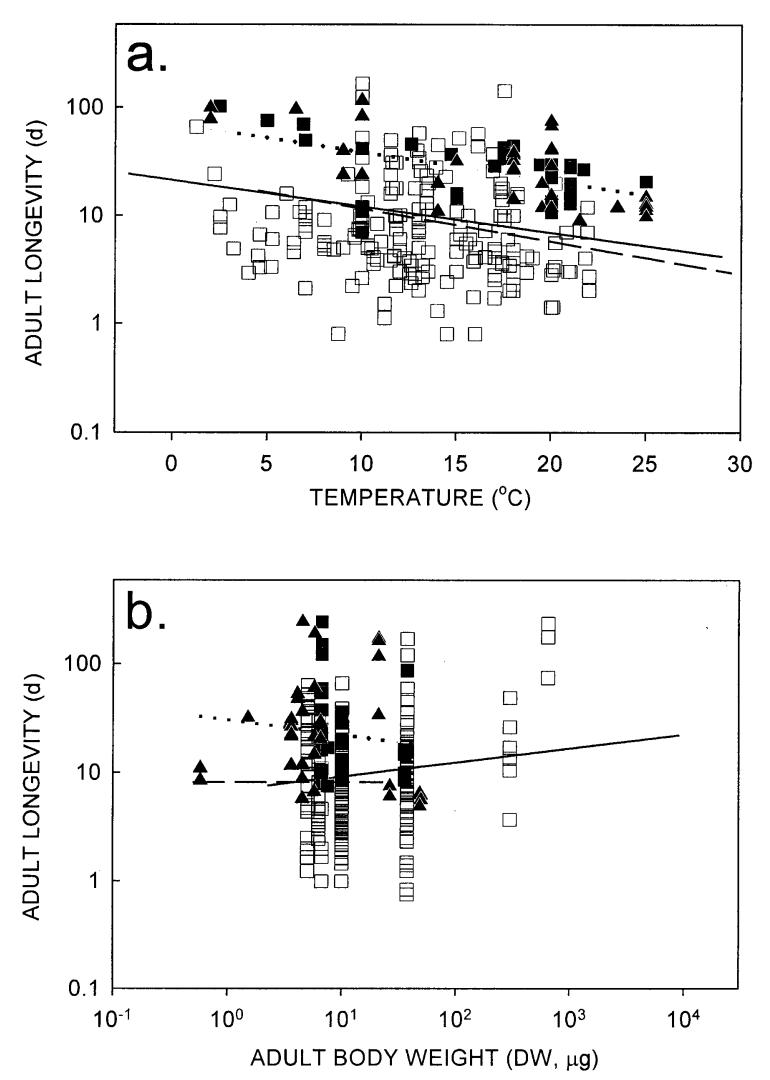

\begin{tabular}{|llll|}
\hline$\square$ & Broadcasters (Field) & a & Broadcasters (Laboratory) \\
$\triangle$ & Sac spawners (Field) & A & Sac spawners (Laboratory)
\end{tabular}

Fig. 7. Adult longevity plotted as a function of (a) temperature $\left({ }^{\circ} \mathrm{C}\right)$ and (b) adult body weight (DW, $\mu \mathrm{g}$ ind ${ }^{-1}$ ) after correction to $15^{\circ} \mathrm{C}$ using a $Q_{10}$ of 2.0 (estimated from the analyses in Fig. 4). Field measurements (open symbols); laboratory measurements (closed symbols); broadcasters (squares); sac spawners (triangles). Predictions of mean adult longevity for broadcasters (solid line) and for sac spawners (dashed line) given for comparison for a $10 \mu \mathrm{g}$ DW individual (a) and at $15^{\circ} \mathrm{C}$ (b). In all cases, predictions were only made within the limits of the regression analysis presented in Figs. 4a,b \& 5a,b. Regressions through all laboratory data (broadcast and sac spawners combined) are given by a dotted line

viduals into a study area could act to give an apparent decrease in mortality too). Our indirect estimates of mortality do not consider advection, except in a sense where these losses are permanent and must be overcome to achieve steady state. The direct measurements of field mortality include changes resulting from advection in a different form, and over different (short) time scales. Some investigators in their experimental design may have chosen sites specifically because they are less subjected to advective loss, and hence facilitate mortality examination; whilst for others, advection may have strongly increased the measured mortality (e.g. Aksnes \& Blindheim [1996] commenting upon

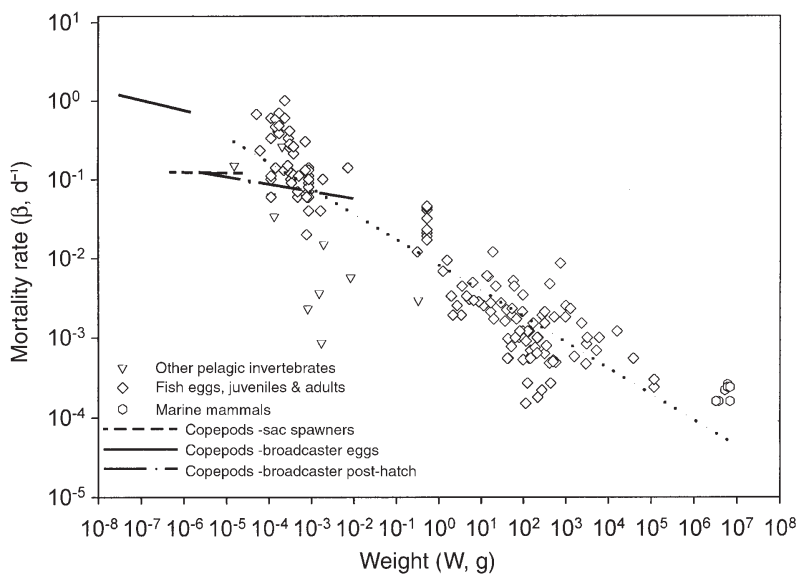

Fig. 8. Mortality rates $\left(\beta, \mathrm{d}^{-1}\right)$ as a function of body dry weight $\left(\mathrm{W}, \mathrm{g}\right.$ ind.$^{-1}$ ) for pelagic invertebrates excluding copepods, eggs, juveniles and adults of fish, and marine mammals (from McGurk 1986). Regression is given by a dotted line $\log _{10} \beta=$ $-0.325 \log _{10} \mathrm{~W}-2.086\left(\mathrm{r}^{2}=0.826, \mathrm{p}<0.001\right)$. Predicted relationships from this study are also given for broadcast eggs (solid line), broadcasters post-hatch (dot-dashed line) and sac spawners (dashed line). For broadcaters post-hatch and sac spawners body weights are taken as adult weights, whereas for the broadcast eggs we use egg weights. All copepod data corrected to $15^{\circ} \mathrm{C}$ using a $Q_{10}$ value of 2.0 (estimated from the analyses in Fig. 4)

Matthews et al. [1978]). Unfortunately, as mentioned in the 'Materials and methods', we cannot quantitatively account for the degree/importance of advection to field mortality as individual studies do not quantify this term.

Peterson \& Wroblewski (1984) predicted that natural mortality rates scale as the -0.25 power of dry weight in juvenile and adult fish. This is similar to the value of -0.32 for mortality rates in pelagic invertebrates, fish and mammals using the data given in McGurk (1986) (Fig. 8). Our predicted mortality rates for broadcast and sac spawning copepods give slopes of -0.09 and -0.01 respectively. Thus, the scaling of mortality with size appears to be far less in copepods than in pelagic organisms in general, although the magnitude of copepod mortality does lie close to the overall general pelagic pattern (Fig. 8). The largest broadcast and sac spawning copepods have mortality rates that fall very close to the pelagic relationship, whilst the smaller broadcast and sac spawning copepods have rates that are lower. This suggests that the smallest copepods avoid mortality that other pelagic organisms of similar size do not.

The indirect predictions of mortality increase with temperature, and the increase is characterised by a $Q_{10}$ of 2 . However, the effect of temperature on development time, and hence mortality, is less than expected on the basis of laboratory observations. Huntley \& Lopez 
(1992) compiled an extensive data set on (mainly laboratory) development times and juvenile growth rates, and found a $Q_{10}$ of 3 . The temperature dependency of development time and fecundity for field populations are less (our development times give a juvenile growth $Q_{10}$ of $\sim 2$ ) or much less (fecundity $Q_{10} \approx$ 1.3 to 1.6$)$. Thus, the growth and fecundity potential appear to be less exploited at higher temperatures, and food limitation more severe at higher than at lower temperatures (see Fig. 3).

\section{Differences between broadcast and sac spawners}

While post-hatch mortalities are of similar magnitude between the 2 spawning groups, the 2 show great differences in the mortality of their eggs. This is not strictly a result of the present analysis, but rather an assumption on which our analyses are based. It is, however, consistent with the direct estimates of mortality (Fig. 6). It seems that post-hatch mortalities of sac spawners are less variable than in broadcasters, in the sense that mortality varies less with body weight and temperature in sac spawners than in broadcast spawners (i.e. slopes are lower). This difference is related to differences in fecundity rather than development time.

The fecundity rates we have compiled are much less variable at any given body size or temperature in sac spawners than in broadcast spawners. Whereas rates of fecundity in broadcasters tend to span more than 3 orders of magnitude, in sac spawners this is less than 2 and often close to 1 . Broadcasters tend to have highly seasonal rates of egg production while for sac spawners rates are much more constant. This has been observed before for single species on a seasonal basis in temperate systems (e.g. Frost 1985, Kiørboe \& Nielsen 1994, Sabatini \& Kiørboe 1995), but our database of egg production demonstrates it across a variety of environments and species (see Figs. 1 \& 2).

There are many possible reasons as to why broadcast egg mortality may be so much greater and more variable than the post-hatch mortality. Egg hatch failure, egg sinking (including higher loss to the benthos) and higher rates of predation and higher advection losses may all play an important role in causing observed egg mortality rates that are up to 3 orders of magnitude larger than post-hatch rates. Dam \& Tang (2001) find that the rates of egg mortality derived from the data of Peterson \& Kimmerer (1994) are probably gross overestimates of the actual possible mortality rates at times. They ascribe the overestimation to differential patchiness of eggs and females, or a lag time between the production of eggs and their sampling, such that a large fraction of eggs sink to the sediment before being sampled, even though these eggs could hatch and re-enter the water column. In shallow water systems, the egg hatching time can be comparable or larger than the time it takes for eggs to sink out of the pelagic realm; this might lead to an apparent decrease in egg production rates derived by the egg ratio method, leading to falsely inflated mortality rates when applying Eq. (4). Many of the egg mortality rate measurements included here have been derived using such a calculation, and egg mortality may therefore be overestimated. Errors are not simply restricted to this method either. Cohort and other vertical life table methods would also be biased if the abundance of eggs in the water column was used, and proportions of eggs which had settled out successfully hatch. It is clear that not only are additional measurements of egg mortality needed, but that measurements need be designed to ensure the eggs are not undersampled.

\section{Sources of mortality}

Adult longevity predicted from our models compares well with measurements on field populations, while both are much shorter than those obtained in the laboratory (Fig. 7). Many factors including food conditions, parasitism, disease and containment artefacts could cause differences between field and laboratory longevity. However, assuming that the differences are predominantly caused by the lack of predation in the laboratory incubations, then we can derive a preliminary first order estimate of predation mortality (i.e. field mortality - laboratory mortality $=$ predation mortality). Uye (1982) in the same way attributed differences between laboratory and field longevity in adults to predation. The lines giving predicted field longevity as a function of temperature (Fig. 7a) have similar slopes of -0.056 for broadcast spawners and -0.071 for sac spawners. The slope for the laboratory data falls between these (at -0.061 ), indicating that the relative magnitude of predation mortality is a constant proportion of total mortality regardless of temperature. At $5^{\circ} \mathrm{C}$, the predicted field longevity is $16.2 \mathrm{~d}$, which translates to a mortality of $0.062 \mathrm{~d}^{-1}$; laboratory longevity is $52.2 \mathrm{~d}$, equating to a mortality of $0.019 \mathrm{~d}^{-1}$. At $25^{\circ} \mathrm{C}$, predicted field mortality is $0.190 \mathrm{~d}^{-1}$ and the laboratory mortality $0.065 \mathrm{~d}^{-1}$. If these differences are due to predation, then this would account for about $2 / 3$ of the total adult mortality regardless of temperature. Hence, both total mortality and predation mortality increase with increasing temperature, but predation is on average a constant proportion of the total mortality. Unfortunately, the range of body sizes over which there are laboratory measurements of longevity is too small to give an indication of whether the proportion of total mortality that is accounted for by predation 
changes with body size. Much of the laboratory data centres around a body size of $\sim 10 \mu \mathrm{g}$ DW. At this size, predicted field longevity is $9.2 \mathrm{~d}$ for broadcasters and $8.1 \mathrm{~d}$ for sac spawners, mortality rates are 0.109 and $0.123 \mathrm{~d}^{-1}$ respectively. The average laboratory longevity is $38.8 \mathrm{~d}$ (for the whole data set), and mortality $0.026 \mathrm{~d}^{-1}$. From these results, predation mortality accounts for $3 / 4$ of the total mortality, similar to that predicted from temperature. These are the first global estimates of predation mortality on copepods of which we are aware. The differences between field and laboratory mortalities are probably conservative because many of the laboratory longevities are underestimates as we include studies in which adult females were collected from the field (longevity measure described as 'postcollection' in Appendix E). Hence, in these cases adults were of unknown age at the outset. If our laboratory longevity is therefore an underestimate of total potential laboratory longevity, then the difference between field and laboratory should be even larger. In conclusion, a large proportion of field mortality in adult copepods is likely to arise from direct predation.

\section{CONCLUSIONS}

We have described indirect estimates of copepod mortality rate and compiled direct field measurements. It is clear that direct estimates of mortality are generally lacking. The predicted rates do not indicate the full extent of the variability in mortality; only direct measurements will give an indication and understanding of the phenomenon of mortality variability over short time and space scales. However, this study brings both predictions and measurements of mortality together, and demonstrates great consistency in the average patterns and rates observed. The mortality rates of broadcast eggs are typically greater than for other stages and these are also the most variable; sampling methodologies by which these rates are obtained need addressing.

The equations we have used to predict development time do not include resource availability. It is possible that with increasing food limitation, rates of development may slow (Durbin et al. 1995) and development time may increase. Analysis by Huntley \& Lopez (1992) of their development time data set demonstrated no difference between natural and laboratory 'food saturated' rates. This might suggest that development times are not strongly influenced by food availability, a conclusion which is supported by laboratory experiments (Berggreen et al. 1988). Fecundity, however, is mostly food limited in the field (Hirst \& Lampit 1998, Kiørboe 1998) and egg production therefore often varies positively with respect to food availability (Kiør- boe et al. 1985, Peterson et al. 1991). We need to point out that our natural rate data set is dominated by estuarine and coastal studies, and is short on oligotrophic open ocean data where food may be much more dilute. Food limitation may increase from coastal to offshore areas, where phytoplankton, microplankton and other prey forms may be more dilute, and copepod fecundity is generally lower (Calbet \& Agustí 1999, Saiz et al. 1999). Using the steady state assumptions we have made here leads us to suggest that mortality rates also decline along such gradients.

Acknowledgements. The authors wish to thank A. D. McKinnon and the anonymous reviewers for comments that improved this paper. We are also indebted to the many people who kindly clarified details of their studies, supplied original data or made suggestions as to sources of data. A.G.H. was funded by the UK Natural Environment Research Council through the thematic programme 'Marine Productivity' (Grant NER/T/S/1999/00057) and T.K. was supported by the Danish Natural Science Research Council (Grant 9801393).

\section{LITERATURE CITED}

Aksnes DL (1996) Natural mortality, fecundity and development time in marine planktonic copepods - implications of behaviour. Mar Ecol Prog Ser 131:315-316

Aksnes DL, Blindheim J (1996) Circulation patterns in the North Atlantic and possible impact on population dynamics of Calanus finmarchicus. Ophelia 44:7-28

Båmstedt U (1986) Chemical composition and energy content. In: Corner EDS, O'Hara SCM (eds) The biological chemistry of marine copepods. Clarendon Press, Oxford, p 1-58

Bautista B, Harris R, Rodriguez V, Guerrero F (1994) Temporal variability in copepod fecundity during two different spring bloom periods in coastal waters off Plymouth (SW England). J Plankton Res 16:1367-1377

Beckman BR, Peterson WT (1986) Egg production by Acartia tonsa in Long Island Sound. J Plankton Res 8:917-925

Berggreen U, Hansen B, Kiørboe T (1988) Food size spectra, ingestion and growth of the copepod Acartia tonsa during development: implications for determination of copepod production. Mar Biol 99:341-352

Borchers P, Hutchings L (1986) Starvation tolerance, development time and egg production of Calanoides carinatus in the Southern Benguela Current. J Plankton Res 8: $855-874$

Calbet A, Agustí S (1999) Latitudinal changes of copepod egg production rates in Atlantic waters: temperature and food availability as the main driving factors. Mar Ecol Prog Ser 181:155-162

Calbet A, Alcaraz M, Saiz E, Estrada M, Trepat I (1996) Planktonic herbivorous food webs in the Catalan Sea (NW Mediterranean): temporal variability and comparison of indices of phyto-zooplankton coupling based on state variables and rate processes. J Plankton Res 18: 2329-2347

Conover RJ, Huntley M (1991) Copepods in ice-covered seas - distribution, adaptions to seasonally limited food, metabolism, growth patterns and life cycle strategies in polar seas. J Mar Syst 2:1-41

Corkett CJ, Urry DL (1968) Observations on the keeping of 
adult female Pseudocalanus elongatus under laboratory conditions. J Mar Biol Assoc UK 48:97-105

Corkett CJ, Zillioux EJ (1975) Studies on the effect of temperature on the egg laying of three species of calanoid copepod in the laboratory (Acartia tonsa, Temora longicornis and Pseudocalanus elongatus). Bull Plankton Soc Jpn 21:77-85

Dam HG, Tang KM (2001) Affordable egg mortality: constraining copepod egg mortality with life history traits. J Plankton Res 23:633-640

Durbin EG, Gilman SL, Campbell RG, Durbin AG (1995) Abundance, biomass, vertical migration and estimated development rate of the copepod Calanus finmarchicus in the southern Gulf of Maine during late spring. Cont Shelf Res 15:571-591

Eiane K (1999) Pelagic food webs: structuring effects of different environmental forcing. DSc thesis, University of Bergen

Frost BW (1985) Food limitation of planktonic marine copepods Calanus pacificus and Pseudocalanus sp. in a temperate fjord. Arch Hydrobiol Beih 21:1-13

Gómez-Gutiérrez J, Peterson WT (1999) Egg production rates of eight calanoid copepod species during summer 1997 off Newport, Oregon, USA. J Plankton Res 21:637-657

Heinle DR (1969) The effects of temperature on the population dynamics of estuarine copepods. $\mathrm{PhD}$ thesis, University of Maryland

Hirst AG, Lampitt RS (1998) Towards a global model of in situ weight-specific growth in marine planktonic copepods. Mar Biol 132:247-257

Hirst AG, Sheader M (1997) Are in situ weight-specific growth rates body size independent in marine planktonic copepods? A re-analysis of the global syntheses and a new empirical model. Mar Ecol Prog Ser 154:155-165

Huntley ME, Lopez MDG (1992) Temperature-dependent production of marine copepods: a global synthesis. Am Nat 140:201-242

Ianora A, Poulet SA (1993) Egg viability in the copepod Temora stylifera. Limnol Oceanogr 38:1615-1626

Jacoby CA, Youngbluth MJ (1983) Mating behavior in three species of Pseudodiaptomus (Copepoda: Calanoida). Mar Biol 76:77-86

Katona SK (1970) Growth characteristics of the copepod Eurytemora affinis and E. herdmani in laboratory cultures. Helgol Wiss Meeresunters 20:373-384

Kimmerer WJ, McKinnon AD (1987) Growth, mortality, and secondary production of the copepod Acartia tranteri in Westernport Bay, Australia. Limnol Oceanogr 32:14-28

Kiørboe T (1998) Population regulation and role of mesozooplankton in shaping marine pelagic food webs. In: Tamminen T, Kuoas H (eds) Eutrophication in planktonic ecosystems: food web dynamics and elemental cycling. Hydrobiologia 363:13-27

Kiørboe T, Nielsen TG (1994) Regulation of zooplankton biomass and production in a temperate, coastal ecosystem. 1. Copepods. Limnol Oceanogr 39:493-507

Kiørboe T, Sabatini M (1994) Reproductive and life cycle strategies in egg-carrying cyclopoid and free-spawning calanoid copepods. J Plankton Res 16:1353-1366

Kiørboe T, Sabatini M (1995) Scaling of fecundity, growth and development in marine planktonic copepods. Mar Ecol Prog Ser 120:285-298

Kiørboe T, Møhlenberg F, Hamburger K (1985) Bioenergetics of the planktonic copepod Acartia tonsa: relation between feeding, egg production and respiration, and composition of specific dynamic action. Mar Ecol Prog Ser 26:85-97
Landry MR (1978) Population dynamics and production of a planktonic marine copepod, Acartia clausii, in a small temperate lagoon on San Juan Island, Washington. Int Rev Ges Hydrobiol 63:77-119

Liang D, Uye S (1997) Population dynamics and production of the planktonic copepods in a eutrophic inlet of the Inland Sea of Japan. IV. Pseudodiaptomus marinus, the eggcarrying calanoid. Mar Biol 128:415-421

Liang D, Uye SI, Onbé T (1994) Production and loss of eggs in the calanoid copepod Centropages abdominalis Sato in Fukuyama Harbour, the Inland Sea of Japan. Bull Plankton Soc Jpn 41:131-142

Matthews JBL, Hestad L, Bakke JLW (1978) Ecological studies in Korsfjorden, Western Norway. The generations and stocks of Calanus hyperboreus and C. finmarchicus in 1971-1974. Oceanol Acta 1:277-284

McGurk MD (1986) Natural mortality of marine pelagic fish eggs and larvae: role of spatial patchiness. Mar Ecol Prog Ser 34:227-242

McKinnon AD (1996) Growth and development in the subtropical copepod Acrocalanus gibber. Limnol Oceanogr 41:1438-1447

Nival S, Pagano M, Nival P (1990) Laboratory study of the spawning rate of the calanoid copepod Centropages typicus: effect of fluctuating food concentration. J Plankton Res 12:535-547

Ohman MD (1986) Predator-limited population growth of the copepod Pseudocalanus sp. J Plankton Res 8:673-713

Ohman MD, Hirche HJ (2001) Density-dependent mortality in an oceanic copepod population. Nature 412:638-641

Ohman MD, Wood SN (1995) The inevitability of mortality. ICES J Mar Sci 52:517-522

Ohman MD, Wood SN (1996) Mortality estimation for planktonic copepods: Pseudocalanus newmani in a temperate fjord. Limnol Oceanogr 41:126-135

Omori M, Ikeda T (1984) Methods in marine zooplankton ecology. Wiley-Liss Inc, New York

Parrish KK, Wilson DF (1978) Fecundity studies on Acartia tonsa (Copepoda: Calanoida) in standardized culture. Mar Biol 46:65-81

Peterson I, Wroblewski JS (1984) Mortality rate of fishes in the pelagic ecosystem. Can J Fish Aquat Sci 41: 1117-1120

Peterson WT, Kimmerer WJ (1994) Processes controlling recruitment of the marine calanoid copepod Temora longicornis in Long Island Sound: egg production, egg mortality, and cohort survival rates. Limnol Oceanogr 39:1594-1605

Peterson WT, Tiselius P, Kiørboe T (1991) Copepod egg production, moulting and growth rates, and secondary production, in the Skagerrak in August 1988. J Plankton Res 13:131-154

Sabatini M, Kiørboe T (1994) Egg production, growth and development of the cyclopoid copepod Oithona similis. J Plankton Res 16:1329-1351

Saiz E, Calbet A, Trepat I, Irigoien X, Alcaraz M (1997) Food availability as a potential source of bias in the egg production method for copepods. J Plankton Res 19:1-14

Saiz E, Calbet A, Irigoien X, Alcaraz M (1999) Copepod egg production in the western Mediterranean: response to food availability in oligotrophic environments. Mar Ecol Prog Ser 187:179-189

Sekiguchi H, McLaren IA, Corkett CJ (1980) Relationship between growth rate and egg production in the copepod Acartia clausi hudsonica. Mar Biol 58:133-138

Smith SL (1990) Egg production and feeding by copepods prior to the spring bloom of phytoplankton in Fram Strait, Greenland Sea. Mar Biol 106:59-69 
Takahashi T, Ohno A (1996) The temperature effect on the development of calanoid copepod, Acartia tsuensis, with some comments on morphogenesis. J Oceanogr 52:125-137

Uye SI (1981) Fecundity studies of neritic calanoid copepods Acartia clausi Giesbrecht and A. steueri Smirnov: a simple empirical model of daily egg production. J Exp Mar Biol Ecol 50:255-271

Uye SI (1982) Population dynamics and production of Acartia

Editorial responsibility: Otto Kinne (Editor),

Oldendorf/Luhe, Germany clausi Giesbrecht (Copepoda: Calanoida) in inlet waters. J Exp Mar Biol Ecol 57:55-83

Uye SI, Sano K (1995) Seasonal reproductive biology of the small cyclopoid copepod Oithona davisae in a temperate eutrophic inlet. Mar Ecol Prog Ser 118:121-128

Uye SI, Yamaoka T, Fujisawa T (1992) Are tidal fronts good recruitment areas for herbivorous copepods? Fish Oceanogr 1(3):216-226

Submitted: July 21, 2001; Accepted: November 15, 2001 Proofs received from author(s): March 18, 2002 